http://dx.doi.org/10.18675/1981-8106.vol23.n43.p5-23

\title{
Ciborgues e monstros em não-lugares: aspectos da educação em uma sociedade supermoderna
}

Henrique Marins de Carvalho Instituto Federal de Educação, Ciência e Tecnologia de São Paulo, campus São Paulo, São Paulo - SP, Brasil. hmarins@yahoo.com

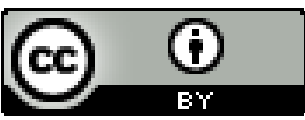

Educação: teoria e prática, Rio Claro, SP, Brasil - elSSN: 1981-8106

Está licenciada sob Licença Creative Common

\section{Resumo}

O sujeito que reside no ambiente escolar recebe a ação de forças específicas que o condicionam a certos comportamentos e determinam aspectos de sua personalidade. No entanto, ele mesmo causa impactos no sistema em que é inserido, por suas características de constante mutação. A Escola é, aqui, percebida como pano de fundo político, social e cultural desse ente social. Com base em algumas ideias de Michel Foucault e da dupla formada por Gilles Deleuze e Felix Guattari faz-se a análise dos instrumentos de poder e das ações neles presentes. Além desses, apresentam-se conceitos apoiados nas definições de Marc Augè, sobre as características do não-lugar na supermodernidade, lugar desprovido de experiência. Para apoiar a observação realizada a respeito do ser que habita a Escola, tomase a ciborgologia, de Donna Haraway, oferecendo a chance de substituir a dicotomia homem versus máquina por uma ontologia do homem-máquina e as sete teses sobre os monstros, de Jeffrey Jerome Cohen que volta o olhar para a monstruosidade que nos cerca. É, portanto, possível identificar o que é a Escola e os entes que são a ela submetidos: um nãolugar repleto de infantes-ciborgues-monstruosos.

Palavras-chave: Supermodernidade. Não-lugares. Ciborgues. Monstros

\section{Cyborgs and monsters on non-places: aspects of education at a supermodern society}

\begin{abstract}
The subject who resides in the school environment receives the action of specific forces guiding the behaviors and fixing certain aspects of personality. However, this same element causes impacts on the system in which it is inserted, by changing their characteristics. The School here is observed as political, social and cultural background of this social entity. Based on some ideas of Michel Foucault and the duo Gilles Deleuze and Felix Guattari is possible to proceed the analysis of the instruments of power and the actions within them. Besides these, we present the definitions of concepts supported Marc Augé, on the characteristics of non-place in supermodernity, place devoid of experience. To support the
\end{abstract}


observation made regarding the being that inhabits the School we use the ciborgology of Donna Haraway, offering the chance to replace the dichotomy of man versus machine by an ontology of human-machine and the seven theses on monsters by Jeffrey Jerome Cohen who looks at the monstrosity that surrounds us. It is therefore possible to identify what are the school and the ones that are submitted to it: a non-place filled of monstrous-cyborginfants.

Keywords: Supermodernity. Non-places. Cyborgs. Monsters.

\title{
1 Introdução
}

\author{
"Is this the real life? \\ Is this just fantasy? \\ Caught in a landslide \\ No escape from reality." \\ (Bohemian Rhapsody-Queen)
}

Qual deve ser a postura adotada por um observador para contemplar as relações estabelecidas em um processo educacional na contemporaneidade? As formas de aquisição e de transmissão de saber empregadas são as mais adequadas para as jovens mentes do século XXI? Quanto há de manutenção de sistemas de poder antigos (quase medievais) no ambiente escolar? A escola é, ainda, necessária?

As respostas a essas questões podem auxiliar a construção de uma atividade de ensino-aprendizagem mais lúcida, bem como interferir nos relacionamentos sociais e culturais periféricos à própria escola. Aqui, a Escola é entendida como o conjunto de todas as tecnologias de poder componentes do ambiente educacional: o espaço, a arquitetura, a administração, as aulas, as avaliações. Os elementos físicos têm sua relevância enquanto padronizações, e os elementos sociais e psíquicos como as pedagogias, as normas de conduta, e, ainda, todos os movimentos interiores de cada indivíduo ocupam seu papel no tecido de relações determinado pelo objetivo da instituição.

Esta meta é pautada na salvação do infante de uma vida do não-saber, que implica, em nossa sociedade, o não-ser, para a vida do conhecimento e, em consequência, do estabelecimento adequado da existência social, conforme diz Foucault $(1977$, p. 71$)$ quando discorre sobre a pedagogia como sistema de normas de formação, desde o século XVIII: “A infância, a juventude das coisas e dos homens estavam carregadas de um poder ambíguo: dizer o nascimento da verdade, mas também colocar à prova a verdade tardia." 
No entanto, apesar de todas as pretensões dessa máquina-escola em sua busca incessante de moldar os que a ela são destinados, o mais ingênuo olhar é capaz de perceber sua precariedade em atender os objetivos que são amplamente divulgados em discursos políticos e pedagógicos como formação cidadã, preparação para a vida e outras falácias que, sempre, são percebidas nos discursos de seus gestores. Há, no entanto, um objetivo menos ostensivo e, mesmo assim, muito mais sentido nas ações rotineiras, que é a manutenção da organização social, com seus nichos de poder social e econômico, infantilizando o corpo do povo, a massa sem identidade que deve ser subjugada.

No anseio de padronizar mentes e corpos, excluindo a possibilidade do anormal, o sistema - extremamente frágil apesar de sua rigidez - constrói blindagens que querem deixá-lo protegido da interferência de qualquer ente que não se ajuste ao estereótipo (masculino, adulto, branco, heterossexual, cristão etc.) sendo atribuídos àqueles que não se encaixem nesse padrão o estigma e a submissão.

Não se mostram alternativas outras (dentre as que apresentam possibilidade razoável de sobrevivência social) aos que já estão imersos nessa imensa rede de elementos que forma o sistema educacional que não sejam:

- sujeitar-se, passiva e comodamente, aos organismos estabelecidos ou

- empreender uma subversão eficaz nos espaços das experiências cotidianas.

Escolher um dos lados nessa guerra e em suas múltiplas batalhas é possível, apenas, àqueles que percebam sua existência e tenham condições de analisar suas ações e consequentes efeitos nos organismos sociais, mesmo reconhecendo, como Foucault, em seu diálogo com Deleuze na obra Microfísica do Poder (1979, p. 42, 44 e 45), que vivemos em um "embaraço em encontrar as formas de luta adequada" por "ignorarmos o que é o poder", mas "cada luta se desenvolve em torno de um foco particular de poder".

Os autores (AUGÈ, 1994; HARAWAY, 2000; COHEN, 2000) tomados como reforço à reflexão são posteriores a Foucault e à dupla Deleuze \& Guattari, e é possível observar o quanto do pensamento dos primeiros pode ser discernido como tendo sido construído sobre os ombros desses últimos, e quão aplicáveis são à análise a respeito da Escola.

Quando se lê as características de um não-lugar, como proposto por Augè (1994), é difícil não relacioná-lo com o ambiente escolar, reduto da eliminação de possibilidades de experiências, antro da racionalização e templo da celebração de uma cultura de morte em 
que, majoritariamente, as emoções latentes são linhas sombrias de revolta, frustração e medo.

A proposta de Haraway (2000), ao eleger o ciborgue (o ser em que não se faz a distinção do que nele é máquina ou humano) como o habitante por excelência da supermodernidade (termo empregado por Augè) longe de recordar personagens de obras ficcionais da literatura ou do cinema, faz olhar e identificar todos na redondeza como ciborgues, inclusive - o que pode ser mais assustador - a si próprio. Seja pela incapacidade de desempenhar as atividades profissionais ou de lazer sem o auxílio de objetos repletos de tecnologia, pela implantação de componentes eletrônicos com a função de melhoria das funções biológicas ou mesmo pelo naufrágio, sem possibilidade de resgate, em um mar de informações controladas, não há sobreviventes humanos em nossa sociedade.

Tomando o caso particular dos indivíduos na escola, em todas as suas instâncias, a presença dessa cultura ciborgue é gritante. Há um discurso frequente, exigindo dos professores sua contínua adequação às novas tecnologias de informação, os cursos e reuniões mediados pela tecnologia tornaram-se um lugar comum e há incentivos financeiros para que os professores adquiram computadores.

No que se refere aos alunos, são massacrados pela publicidade de novos (mas sempre descartáveis) telefones celulares e outros dispositivos, com recursos de som, vídeo, jogos, um sem-fim de alternativas com a finalidade de formar consumidores para a manutenção dos amplos lucros desse segmento comercial.

Até mesmo as instituições de administração e fomento da educação salientam, com suas diretrizes, que a aquisição e o uso de equipamentos tecnológicos na escola são metas quase essenciais para a melhoria do processo de aprendizagem.

Já Cohen (2000) sugere, com suas proposições sobre os monstros e sua influência na cultura dos homens, uma maneira de analisar o que também é monstruosidade nos indivíduos e em suas relações sociais. Ao identificar o monstro como uma invenção social, gerada pelas diferenças e potencializada pelos conflitos de classes, abre caminho para que se percebam todos os diferentes como monstros: temidos por apresentar agressivamente sua individualidade, secretamente admirados em sua anomalia e desejados por sua capacidade de ser ou tornar-se aquilo que rompe com a mediocridade e liberta para a experiência de algo que não é o mesmo. 


\title{
2 Ciborgues e monstros: indivíduos da supermodernidade
}

\subsection{Ciborgues: quando a ficção e realidade se confundem}

\author{
"Pane no sistema, alguém me desconfigurou \\ Aonde estão meus olhos de robô? \\ Eu não sabia, eu não tinha percebido \\ Eu sempre achei que era vivo \\ Mas lá vem eles novar \\ E eu sei o que vão fazer: \\ Reinstalar o sistema \\ Leia, vote, não se esqueça \\ Use, seja, ouça, diga... \\ Não senhor. Sim senhor" \\ (Admirável Chip Novo - Pitty)
}

Ciborgue (no original, cyborg) é um termo criado em 1960, pelo engenheiro Manfred Clynes e pelo psiquiatra Nathan Kline, como uma abreviação de cybernetic organism, em um artigo que descrevia a experiência realizada em um rato de laboratório no qual foi implantada uma bomba que liberava doses de substâncias químicas para alterar suas funções fisiológicas.

No pensamento dessa dupla, a possibilidade da associação do organismo biológico à máquina (e vice-versa) possibilitaria a gênese de um homem ampliado, libertado de parte de suas limitações e capaz de enfrentar desafios como as viagens espaciais (KUNZRU, 2000).

Já o termo cibernético, empregado pelo matemático do Massachussets Institute of Technology, Norbert Wiener, em artigo de 1948, tem sua raiz no verbete grego kybernetes, que se refere àquele que dirige, que conduz, como um timoneiro em sua missão de levar a nave com suavidade pelos mares, observando os fenômenos naturais e alterando o curso quando for necessário.

Graças aos desenvolvimentos tecnológicos que, em diversas situações confundem-se com ou mesmo se baseiam em obras de ficção, a sociedade supermoderna sente, então, a necessidade de desenvolver novas normas sociais, novas leis, novas relações de trabalho, novos estudos científicos, enfim, uma revisão completa da coleção de saberes e práticas humanas até o momento estabelecidas.

Haraway (2000, p. 36), em seu Manifesto Ciborgue, apresenta o ciborgue como "uma criatura da realidade social". Percebendo a presença da realidade ciborgue na ficção, na medicina, nas guerras recentemente empreendidas pelas potências bélicas mundiais, e 
mesmo nos relacionamentos pessoais, afirma, também, que "somos todos quimeras, híbridos - teóricos e fabricados - de máquina e organismos" (Haraway, 2000, p. 37).

A partir do momento em que se elimina a necessidade de estabelecer claramente onde termina o homem e onde começa a máquina, possibilitando perceber o ciborgue como uma criatura que é univocamente definida por sua multiplicidade, desconstrói-se os discursos que levam à totalidade. Assim, o ciborgue não é atingido pelo desejo edipiano, porque, enquanto homem-máquina, ele se fragmenta e se restitui sem o desejo de possuir ou de se identificar a seus progenitores; não anseia, tampouco, por uma redenção apocalíptica, pois, se ele não é formado a partir de uma natureza unificadora, seu destino não tem de sê-lo.

Confundindo em si mesmo a unicidade e a multiplicidade, este ser rizomático, ao mesmo tempo em que apresenta conflitos, é libertador, justamente ao estabelecer, por sua existência, linhas de força que unem todas as máquinas de desejo que o constituem. Como afirmam Deleuze e Guattari (2000a, p. 3) “é preciso fazer o múltiplo, não acrescentando sempre uma dimensão superior, mas, ao contrário, sempre n-1 (é somente assim que o uno faz parte do múltiplo, estando sempre subtraído dele.)".

Nesse ser híbrido notam-se, fulgurantes, os princípios eleitos por Deleuze e Guattari (2000a) postulando sobre o rizoma:

- conexão e heterogeneidade - não há nenhum ciborgue que exista sem a vinculação a uma rede de saberes. Na verdade, todos nós permanecemos mergulhados em inúmeras, e cada vez mais ágeis, redes de comunicação. Até em nosso linguajar cotidiano emoções são expressas com o emprego de termos oriundos da tecnologia de informação (são comuns termos e frases como: está ligado?, estar plugado, conectividade).

- Multiplicidade - múltiplo em seu hibridismo, o ciborgue é capaz de abrigar cada vez mais máquinas em sua reinvenção constante. Um corpo sem órgãos, inscrevendo novos agenciamentos e eliminando sua finitude.

- Ruptura a-significante - as segmentaridades existentes no ciborgue têm a característica de mobilidade, causando um movimento de desterritorialização e novas estratificações a todo instante. Cada nova máquina assimilada causa novo conjunto de linhas de força e de fuga, provocando mutações periódicas, mas nenhuma alteração é capaz de destituir o ciborgue de sua essência. 
- Cartografia e de decalcomania - ao transitar pelas redes, o ciborgue mapeia as conexões que estabelecem uma coletividade tecno-humana e, em cada trânsito no mundo real ou no virtual, abandona traços de si, assim como se contamina por algo do ambiente em que esteve. Torna-se, assim, mais que um mecanismo de transporte de informações, um transeunte de circuitos, peregrino de fluxos.

O ciborgue é nascido do conflito de saberes, é fruto de todos os levantes políticos, sociais e científicos deste século e do anterior; e exige, enquanto se vê instaurar o incômodo de sua presença, uma nova ontologia, visto que seu ser é outro; novas ética e moral, pois as que herdaram dos humanos são incompletas ou contraditórias; uma psicologia que atenda à sua característica multifacetada, enfim, todo um novo corpo de conhecimentos retomados em função dessa nova entidade. Também a política, a medicina, o entretenimento, as religiões são atingidas pela fratura epistemológica causada pelos ciborgues.

A antitética relação homem-máquina não faz mais nenhum sentido, já que todos fazem parte desse emaranhado de redes de informação e controle que atam como barbantes invisíveis de um títere, simulando seus movimentos e criando a ilusão de liberdade.

A ficção científica, na literatura ou no cinema, tem exemplos impressionantes de máquinas (computadores, robôs, andróides) que, criados pelo homem, evoluem até o nível de consciência que os leva a, em alguns casos, ansiar por uma existência igualada à dos humanos; por exemplo, o robô Andrew Martin, do conto "O Homem Bicentenário" (ASIMOV, 2001) que leva seu desejo pela humanidade até a última consequência ao solicitar uma modificação de seu cérebro positrônico que o permita experimentar a totalidade do ser humano, incluindo a morte.

Em outros casos, mais assustadores, as máquinas sensientes acabam decidindo sobrepujar seus criadores e submetê-los à condição de servos, como é o caso da trilogia Matrix, lançada entre 1999 e 2003, dirigida pelos irmãos Andy Wachowski e Larry Wachowski, em que as máquinas, após a guerra empreendida contra os humanos, criam um aprisionamento que, simultaneamente, cria a ilusão de uma vida normal enquanto se vale da energia dos corpos para sua própria sobrevivência.

Os ciborgues são frutos das ações políticas e sociais de nossa sociedade e não deveriam ser infantilizados, porque não há meios de classificá-los por nossos padrões de referência. Cabe aos espíritos livres reconhecer as possibilidades de sujeição, cônscia e 
voluntária, a tal sistema que estabelece a confusão do tecnológico com o biológico e aceitála. Talvez, dessa sorte, sabedor de suas limitações e potências, possa ser construída a figura do neo-humano, o ser ampliado, melhorado, menos condicionado a uma cultura unificadora que a uma infinidade de alternativas.

Parece que Foucault, ao escrever a Introdução à vida não-fascista, prefácio de "O Anti-Édipo: Capitalismo e Esquizofrenia", de Deleuze e Guattari (DELEUZE; GUATTARI, 2004) preconizava, antecipadamente, um modus vivendi para um ciborgue imerso na sociedade.

\footnotetext{
- Libere a ação política de toda forma de paranóia unitária e totalizante; - Faça crescer a ação, o pensamento e os desejos por proliferação, justaposição e disjunção, mais do que por subdivisão e hierarquização piramidal;

- Libere-se das velhas categorias do Negativo (a lei, o limite, a castração, a falta, a lacuna), que o pensamento ocidental, por um longo tempo, sacralizou como forma do poder e modo de acesso à realidade. Prefira o que é positivo e múltiplo; a diferença à uniformidade; o fluxo às unidades; os agenciamentos móveis aos sistemas. Considere que o que é produtivo, não é sedentário, mas nômade;

- Não imagine que seja preciso ser triste para ser militante, mesmo que a coisa que se combata seja abominável. É a ligação do desejo com a realidade (e não sua fuga, nas formas da representação) que possui uma força revolucionária;

- Não utilize o pensamento para dar a uma prática política um valor de verdade; nem a ação política, para desacreditar um pensamento, como se ele fosse apenas pura especulação. Utilize a prática política como um intensificador do pensamento, e a análise como um multiplicador das formas e dos domínios de intervenção da ação política;

- Não exija da ação política que ela restabeleça os "direitos" do indivíduo, tal como a filosofia os definiu. $O$ indivíduo é o produto do poder. O que é preciso é "desindividualizar" pela multiplicação, o deslocamento e os diversos agenciamentos. O grupo não deve ser o laço orgânico que une os indivíduos hierarquizados, mas um constante gerador de "desindividualização";

- Não caia de amores pelo poder.
}

O ciborgue assume em plenitude tais orientações, pois ele é a multiplicidade concretizada, desalienada de qualquer política e, ainda assim, militante. Nada há nele que seja negação, posto que tudo pode ser assimilado em prol da melhoria do próprio ser de toda a rede na qual está inserido. A ciência, que cria esse tecno-humano, interfere nos sistemas de poder, pois como estabelece Foucault, na obra Arqueologia do Saber (1987a, p. 207):

A influência da ideologia sobre o discurso científico e o funcionamento ideológico das ciências não se articulam no nível de sua estrutura ideal (mesmo que nele possam traduzir-se de uma forma mais ou menos visível), nem no nível de sua utilização técnica em uma sociedade (se bem que esta possa aí entrar em vigor), nem no nível da consciência dos sujeitos que a constroem; articulam-se onde a ciência se destaca sobre o saber.

\subsection{Monstros: temidos e desejados}


"Something's wrong, shut the light, heavy thoughts tonight And they aren't of snow white Dreams of war, dreams of liars, dreams of dragon's fire, And of things that will bite

Hush little baby, don't say a word, And never mind that noise you heard

It's just the beast under your bed, In your closet, in your head."

(Enter Sandman - Metallica)

Jeffrey Cohen (2000, p. 26), a partir de sua experiência no estudo da cultura medieval e contemporânea, esquivando-se da tentação de criar uma única teoria sobre os monstros, enuncia sete postulados que Ihe permitem interpretá-los, bem como aos elementos que os constituem.

- O corpo do monstro é um corpo cultural;

- o monstro sempre escapa;

- o monstro é o arauto da crise de categorias;

- o monstro mora nos portões da diferença;

- o monstro policia as fronteiras do possível;

- o medo do monstro é realmente uma espécie de desejo;

- o monstro está situado no limiar do tornar-se.

O monstro, como invenção cultural, é um vórtice para o qual convergem as emoções de certo grupo. Elegendo esse ícone místico, esse corpo cultural, cria-se um rito que o mantém na lembrança - seja para utilizar o medo que produz nos demais como elemento disciplinador, seja para reconhecer em suas deformidades as próprias imperfeições da sociedade. Consoante com a discussão feita por Foucault (1999, p. 95) na Aula de 28 de janeiro de 1976 do curso Em Defesa da Sociedade, sobre os discursos a respeito dos estrangeiros para justificar ações racistas das instituições de Estado, os monstros também são, em muitos casos, estereótipos dos "estrangeiros que se infiltraram, dos transviados que são subprodutos da sociedade". Os relatos fabulosos vão, assim, dar vazão a atitudes de repressão e segregação daqueles considerados anormais.

A anormalidade é segregada, mas o monstro nunca é totalmente eliminado, porque reside, como diz Cohen (2000, p. 32), nos "portões da diferença" e é indestrutível. Mesmo 
que um exemplar seja capturado, eliminado ou sujeitado à normalidade, outros continuarão existindo, perpetuando esse elemento de tenebrosa instabilidade.

A fuga do monstro, presente nas histórias, reflete a carência sentida pelo ser social em encontrar, muitas vezes, linhas de escape que lhe permitam experimentar a alteridade e o anseio reprimido por tal experiência.

A própria menção do monstro já alerta sobre os conflitos, interiores ou sociais, e determina os limites do que pode ser realizado, seja o Lobo Mau, impedindo os pequenos de explorar as florestas que circundavam as aldeias; o temível Krakken, que fazia os navegadores repensarem as rotas de seus navios; ou a grotesca criatura inventada pelo conselho de anciões no filme $A$ Vila, de M. Night Shyamalan que impedia a saída para o mundo exterior.

Nas fronteiras inexploradas há sempre a lembrança de um monstro que alerta sobre os perigos da jornada, atuando como uma salvaguarda que, ao criar o temor do desconhecido, insiste na segurança do reduto e interrompe o fluxo do desejo pelo novo.

Tais criaturas são parte integrante de nossa cultura - personagens que abrigam as histórias de terror contadas ao redor de fogueiras ou exibidas em salas de cinema - e, ao buscar entendê-las, pode ser que se entenda, também, aquilo que as inventou, pois se trata de uma criação que não estabelece uma gênese destruidora dos instrumentos então existentes, mas como que reencanta o mundo, apropriando-se do que existe para estabelecer esse novo ser.

O medo do monstro esconde uma admiração velada por sua liberdade, seu desapego às normas de conduta e pela forma como ele subverte o condicionamento do que unifica a massa sociocultural. Ao relatar as façanhas de seres alienígenas, o contador de histórias está tão somente elaborando crônicas de aventuras que gostaria de experimentar e essa experiência simulada acaba por ser sua forma de se libertar da mesmice cotidiana.

Tais seres podem ser vistos, ainda, como uma representação espetacular do sonho esquizofrênico descrito por Deleuze e Guattari, no capítulo intitulado 1914 - Um só ou vários lobos?:

Estou na borda desta multidão, na periferia; mas pertenço a ela, a ela estou ligado por uma extremidade de meu corpo, uma mão ou um pé. Sei que esta periferia é o meu único lugar possível, eu morreria se me deixasse levar ao centro da confusão, mas também, certamente, se eu abandonasse a multidão (2000a, p.40). 
Vários são os exemplos de monstros que possuem personalidades alternadamente antitéticas: gentis e monstruosas. O conde Drácula é representado em várias versões cinematográficas (notoriamente na de Francis Ford Coppola) como um nobre; a lenda do lobisomem sempre está atrelada à existência de um homem comum que, por alguma maldição, se transforma em lobo em determinadas ocasiões e, em especial, o personagem duplo do conto de Robert Louis Stevenson: o médico e o monstro (The strange case of Dr. Jekyll and Mr. Hide). Em qualquer um desses casos, ocorre o mesmo turbilhão de sensações, perceptível no relato do sonho. Não é um único desejo, não é uma única personalidade, mas uma multiplicidade habitando um corpo e uma mente.

Novamente, contemplando os infantes arremessados no interior dos estabelecimentos de ensino, não há como não percebê-los como espécimes adequados para identificar e analisar esses postulados sobre monstros ora enunciados e brevemente comentados.

Os infantes trazem em si uma das características mais inerentes aos monstros: a diferença. Por ser um adulto em potencial, é diferente do adulto já estabelecido; por ainda não ter adquirido as competências culturais e sociais, é diferente, por possuir uma infinidade de potencialidades, sem ter realizado ainda nenhuma delas, é diferente. Essa diferença assusta tanto que sobre o infante recai toda a força de um sistema que vigia e adestra.

O mesmo espanto causado pelo monstro acomete a sociedade constituída de seus indivíduos classificados como normais quando se defronta com qualquer anormalidade. Assim, o que diz Foucault sobre a loucura pode muito bem ser aplicado a qualquer monstruosidade:

\begin{abstract}
A história da loucura seria a história do Outro - daquilo que, para uma cultura é ao mesmo tempo interior e estranho, a ser portanto excluído (para conjurar-lhe o perigo interior), encerrando-o porém (para reduzir-lhe a alteridade); a história da ordem das coisas seria a história do Mesmo - daquilo que, para uma cultura, é ao mesmo tempo disperso e aparentado, a ser portanto distinguido por marcas e recolhido em identidades. (FOUCAULT, 1992, p. XXI)
\end{abstract}

Um mundo de não-lugares

"Viajei por mais terras do que aquelas em que toquei... $\mathrm{Vi}$ mais paisagens do que aquelas em que pus os olhos... Experimentei mais sensações do que todas as sensações que senti, Porque, por mais que sentisse, sempre me faltou que sentir E a vida sempre me doeu, sempre foi pouco, e eu infeliz." (trecho de Passagem das Horas - Álvaro de Campos) 
Augè (1994, p. 33-42) sugere o termo supermodernidade para classificar a era histórica atual, caracterizando sua existência a partir de três elementos que são facilmente percebidos: a superabundância factual, a superabundância espacial e individualização de referências.

A superabundância factual se faz notar pelo incremento da quantidade de informações disponibilizadas, e pela velocidade de sua transmissão. Os indivíduos são atingidos, diuturnamente, por uma avalanche de notícias, muitas vezes mesmo sem estar efetivamente em busca de tais conteúdos. Novos produtos e seus softwares são apresentados a cada temporada, como sendo a atual (e logo superada) tecnologia indispensável para a comunicação humana (ou ciborgue).

Nota-se a superabundância espacial pelo reconhecimento de paisagens nunca visitadas, a velocidade sempre crescente dos meios de transporte, os ambiente múltiplos de habitação (casa, escola, trabalho, lazer). Esta superabundância espacial acaba por causar uma necessidade latente de múltiplas identificações, uma esquizofrenia sistematizada.

A terceira face da supermodernidade é a individualização de referências, percebida pelo egocentrismo que norteia a maior parte dos relacionamentos interpessoais. O anseio pelos espaços e objetos de consumo personalizados (customizados) manifesta a presença desse conceito.

A associação de tais elementos que caracterizam a supermodernidade também propicia a observação daquilo que Augè (1994) classifica como não-lugares. Tomando inicialmente a distinção entre espaços e lugares, definida por Certeau apud Augè (1994, p. 75), o que difere lugares de não-lugares é a possibilidade da experiência. Um não-lugar é apenas uma passagem, uma via, em que a efêmera existência de um ser habitante não se prolonga por mais que o tempo entre o seu uso e posterior descarte.

Nos não-lugares inexiste o vínculo, a sensação de pertença, a celebração ou sacralização de qualquer elemento humano. É a profanação plena dos ambientes, que são percorridos, não afetando o viajante, que, destituído de qualquer possibilidade de experiência, prossegue em uma jornada interminável cujo objetivo nem sempre é claro.

No não-lugar nada é experiência, nada é sagrado. O acúmulo de informações pretende ocupar o vazio deixado pela possibilidade de afetação, a racionalização se sobrepõe à mítica relação entre o indivíduo e o fenômeno. Tudo é excesso e, ainda assim, nada tem verdadeiramente valor. 
O declínio da experiência, referido por Benjamin apud Agamben $(2005$, p. 7) e apresentado em minúcias por Agamben (2005, p. 22) se exerce em plenitude em um nãolugar.

O dia-a-dia do homem contemporâneo não contém quase nada que seja inda traduzível em experiência: não a leitura do jornal, tão rica em notícias do que lhe diz respeito a uma distância insuperável; não os minutos que passa, preso ao volante, em um engarrafamento; não a viagem às regiões ínferas nos vagões do metrô nem a manifestação que de repente bloqueia a rua; não a névoa dos lacrimogêneos que se dissipa lenta entre os edifícios do centro e nem mesmo os súbitos estampidos de pistola detonados na se sabe onde. [...] O homem moderno volta para casa à noitinha extremado por uma mixórdia de eventos - divertidos ou maçantes, banais ou insólitos, agradáveis ou atrozes -, entretanto nenhum deles se tornou experiência.

A Escola é um não-lugar. Seus elementos humanos não se sentem habitantes, mas passageiros; a sacralização do espaço por ritos que propiciem a experiência de eventos é substituída - quando muito - pela repetição de falsos rituais feitos de palavras e gestos esvaziados de significado e de valor, mesmo por aqueles que exigem sua realização.

A Escola que poderia existir como um verdadeiro lugar, isto é, como um agenciamento de desejos (desejo de ensinar, de aprender, de se relacionar) é substituído pelo não-lugar em que tudo se estratifica, se normatiza. O não-lugar, também se valendo das definições de Deleuze e Guattari (2000b, p. 157), é muito mais um espaço sedentário que uma máquina de guerra nômade, um "espaço constantemente estriado sob a coação de forças que nele se exercem".

Confluências de ações e pensamentos que poderiam levar a construções sociais mais vibrantes e valiosas experiências praticamente inexistem e são abafadas pelas rotas, caminhos pelos quais os infantes devem transitar, almejando o destino da vida adulta, como elemento produtivo da sociedade gerida pelo capital. Mais aterrador ainda é perceber que ao encerrar o trânsito por essa escola-passagem, o indivíduo é absorvido pela massa social e é arremessado em novas rotas e destinos: a empresa-passagem, o clube-passagem, o condomínio-passagem.

Um caminho não é necessariamente algo ruim, mas os não-lugares cruelmente castram as possíveis relações entre seus elementos, pois além de não serem habitantes, não são nem mesmo peregrinos. O peregrino, apesar de (e em virtude de) sua condição itinerante, é capaz de atravessar a paisagem, misturando-se com ela, tendo em cada passo, uma nova gama de possibilidades de cores, sons e cheiros. Ele é o habitante da unicidade do momento. A destinação determinada a priori não é o aspecto mais relevante da 
peregrinação, pois, ao ser atingida, esta findará. Ao contrário, a peregrinação é válida em si mesma, pela múltipla possibilidade de experiências que possibilita.

Aos indivíduos da supermodernidade, no entanto, só resta o papel de transeuntes e não lhes é dado o privilégio de desperdiçar seu tempo olhando ao redor, não há a concessão de voltar e refazer o caminho ou alterá-lo e, em hipótese alguma, é facultada a interrupção do movimento.

O deslocamento frenético explora o excesso espacial, que ilude ao supor que a exposição demasiada de paisagens e roteiros virtuais nos documentários da televisão e as visitas tridimensionais a museus disponíveis em sítios da teia mundial de computadores são capazes de substituir a experiência de tais eventos.

Muitas vezes, com o suporte do discurso da mais recente pedagogia salvadora, contaminam-se os espaços do ambiente escolar com recursos tecnológicos, prometendo o treinamento para enfrentar a sociedade da informação atual, porém uma observação que pode ser julgada como pessimista dirá que a escola só está - mais uma vez - cumprindo sua terrível missão de fortalecer a estratificação social e propiciar uma massa devidamente lobotomizada, um rebanho a ser perenemente conduzido pelos caminhos determinados pelos organismos fascistas do sistema.

\section{Escola: um não-lugar habitado por monstros e ciborgues}

"Eu tô aqui pra quê? Será que é pra aprender?

Ou será que é pra sentar, me acomodar e obedecer? Tô tentando passar de ano pro meu pai não me bater Sem recreio, de saco cheio porque eu não fiz o dever

Eu gosto dos professores e eu preciso de um mestre Mas eu prefiro que eles me ensinem alguma coisa que preste

Pois na escola é onde formamos nossa personalidade Vocês tratam a educação como um negócio onde a ganância a exploração e a indiferença são sócios Quem devia lucrar só é prejudicado." (Estudo Errado - Gabriel o Pensador)

De maneira bastante especial, cabe aqui uma abordagem sobre o que toca à Escola nessa instável situação em que boa parte dos instrumentos científicos, sociais e jurídicos aparenta não ter mais nenhuma validade ou estão abalados pela transição e é notável uma 
sensação coletiva peculiar a este momento de mudança, algo como a apneia que precede o salto no abismo ou como a ampliação dos sentidos em um momento de temor extremo.

Retomando Haraway (2000), que procura identificar as redes de poder e conceituar os loci sociais nos quais os ciborgues estão inseridos, surgem algumas características marcantes da Escola assim pensada:

Escola: vínculos aprofundados entre as necessidades do capital high-tech e a educação pública em todos os níveis, diferenciados por raça, classe e gênero; as classes executivas envolvidas na reforma educacional e no refinanciamento (...) para as crianças e os professores; educação para a ignorância em massa e a repressão, em uma cultura militarizada e tecnocrática; (...) crescente orientação industrial da educação (especialmente a superior) sob a liderança das multinacionais de produção baseada na ciência; (...) elites altamente educadas e numerosas, em uma sociedade progressivamente bimodal (HARAWAY, 2000, p. 79-80).

Todo esse sistema educacional se apropria das potencialidades e multiplicidades de seus elementos, mas longe de permitir-lhes um desenvolvimento de suas capacidades, condiciona-os a procedimentos repetitivos e uma absorção de aprendizados estéreis; frustra o desejo de uma existência aperfeiçoada enquanto enaltece a mediocridade.

Assim, mesmo os discursos pedagógicos mais atraentes e aparentemente ingênuos, têm uma crueldade latente, por serem instrumentos de ação do poder (ou de micropoderes). Os gestores educacionais que se enamoram dos textos legislativos e das diretrizes poluídas pela política e pela economia parecem reproduzir o terror do personagem do conto O livro de Areia quando diz:

O verão declinava e compreendi que o livro era monstruoso. De nada me serviu considerar que não menos monstruoso era eu, que o percebia com olhos e o apalpava com dez dedos com unhas. Senti que era um objeto de pesadelo, uma coisa obscena que infamava e corrompia a realidade (BORGES, 1984).

Os espíritos dos infantes, aprisionados por tal escola permanecem metamorfoseados como bestas de carga, mas quase nunca experimentam a segunda das metamorfoses que Ihes tornariam leões, altivos e autônomos (NIETZSCHE, 2002).

Incoerentemente, a criança, sequestrada pelo sistema do seio familiar, é arrastada para uma usina que tenciona forjar sua mente e seu corpo e eliminar o telos de seu espírito: ser livre, ou seja, ser criança.

Enquanto a alteridade incomodar tanto, obrigando o estabelecimento de um regime disciplinador, o destino dos diferentes continuará sendo a exclusão (se não o asilo físico, ao 
menos o social) e os infantes ciborgues ou os infantes monstros continuarão não possuindo nenhuma possibilidade de exercer a autonomia que viria a evoluir seu espírito.

Esses seres arremessados nas engrenagens do sistema recebem o impacto fulgurante de vários instrumentos do poder, e muitos são percebidos somente pelas escriturações comuns no ambiente escolar (nos diários escolares, atas de conselhos de classe ou registros de ocorrência) semelhante às lettres de cachet relatadas por Foucault $(1992$, p. 117) em "A vida dos homens infames":

Todas aquelas coisas que constituem o ordinário, o pormenor insignificante, a obscuridade, os dias sem glória, a vida comum, podem e devem ser ditas, - mais, escritas. Tornam-se descritíveis e transcritíveis, na própria medida que são atravessadas pelos mecanismos de um poder político.

Ainda de acordo com Foucault (1999, p. 116-122), na explanação transcrita em "A verdade e as formas jurídicas", a escola desempenha funções que também são compartilhadas por outras instituições do Estado como as prisões, os hospitais, os asilos de loucos e as fábricas:

- controlar a totalidade da vida (e do tempo) dos indivíduos;

- forjar e manter os corpos dos indivíduos;

- criar (micro) poderes econômicos, políticos e judiciários e

- extrair saberes das práticas sociais .

Se esta obliteração de potencialidades causa incômodo, deve também impelir à revolução, não um levante bélico nem de largas proporções, pois, assim, só resultaria em outra forma de sujeição, mas uma contravenção pautada pela subversão extremamente planejada e realizada no momento adequado, atingindo o sistema naquele conceito que lhe é mais caro e é sua maior fraqueza: o discurso totalitário.

Qualquer ação que frature esse totalitarismo político e cultural já é uma vitória considerável em favor de um devir-monstro ou devir-ciborgue, em suma, da liberdade de ser outro.

\section{Um não-final (ou seria um quase-começo...)}

"Eu prefiro ser essa metamorfose ambulante Do que ter aquela velha opinião formada sobre tudo Eu quero dizer, agora, o oposto do que eu disse antes

Eu prefiro ser essa metamorfose ambulante"

(Metamorfose ambulante - Raul Seixas) 
Um artesão, ao juntar matérias díspares moldando uma nova peça, ou um poeta, ao aglutinar palavras em um novo corpo de sentidos, só terão sucesso em sua empreitada quando ocorrer o encontro entre sua obra e um leitor disposto a ser afetado por ela.

Ao apresentar a Escola como um ambiente desprovido de experiência não se pretende sugerir um movimento revolucionário em larga escala que diga abaixo a Escola!, muito contrariamente anseia-se por uma Escola em que as relações humanas (ou ciborgues) causem um emaranhado tal de forças e poderes que permitam ao sujeito que nela está inserido usufruir de resultados de seu desprendimento de energia, podendo chegar ao ponto que este mesmo indivíduo, no usufruto máximo de suas capacidades de escolha e de consciência, após vivenciar - segundo Nietzsche - todas as metamorfoses do espírito, tome posse dos vetores de força e de poder existentes, e os dirija conforme sua própria vontade.

Tampouco, a descrição desse elemento como um ciborgue-monstro anseia por causar espanto ou ojeriza em quem com eles precisa travar contato, mas possibilitar a preparação para os enfrentamentos que são necessários. As lutas a serem travada pelos educadores, em qualquer ambiente, não se assemelham às estratégias de grandes exércitos em um campo de batalha senão a ações de guerrilha e micro-revoluções que, aos poucos, se multiplicam e agridem o sistema em suas estruturas rígidas e opressoras.

Dessa forma, possa este emaranhado de saberes - bricolagem de fluxos de ideias e de autores - resultar em inquietação ou consentimento de pensares. Ou ambos.

\section{Referências}

AGAMBEN, G. Infância e História: destruição da experiência e origem da história. Belo Horizonte: Editora UFMG, 2005.

ASIMOV, I. O homem bicentenário . Porto Alegre: L\&PM, 2001.

AUGÈ, M. Não-Lugares: Introdução a uma antropologia da supermodernidade. São Paulo: Papirus, 1994.

BORGES, J.L. O Livro de Areia. Trad. Rio de Janeiro: Editora Globo, 1984. 
COHEN, J. J. A cultura dos monstros: sete teses. In: SILVA, T.T. (Org.) Pedagogia dos Monstros: Os Prazeres e os Perigos da Confusão de Fronteiras. Belo Horizonte: Autêntica, 2000.

DELEUZE, G.; GUATTARI, F. O Anti-Édipo: Capitalismo e Esquizofrenia. Lisboa: Assírio \& Alvin, 2004.

DELEUZE, G.; GUATTARI, F. Mil Platôs - capitalismo e esquizofrenia. V. 1. Rio de Janeiro: Editora 34, 2000a.

DELEUZE, G.; GUATTARI, F. Mil Platôs - capitalismo e esquizofrenia. V. 5. Rio de Janeiro: Editora 34, 2000b.

FOUCAULT, M. A Arqueologia do Saber. Rio de Janeiro: Editora Forense-Universitária, 1987a.

FOUCAULT, M. A Ordem do Discurso. São Paulo: Edições Loyola, 2000.

FOUCAULT, M. As Palavras e as Coisas. São Paulo: Livraria Martins Fontes Editora Ltda, 1992.

FOUCAULT, M. Em Defesa da Sociedade: curso no Collège de France (1975-1976). São Paulo: Martins Fontes, 1999.

FOUCAULT, M. Microfísica do Poder. Rio de Janeiro: Edições Graal Ltda, 1979.

FOUCAULT, M. Vigiar e Punir: nascimento da prisão. Petrópolis: Vozes, 1987b.

HARAWAY, D. J. Manifesto Ciborgue. Ciência, tecnologia e feminismo-socialista no final do século XX. In: SILVA, T. T (Org.) Antropologia do Ciborgue: as vertigens do pós-humano. Belo Horizonte: Autêntica, 2000.

KUNZRU, H. Genealogia do ciborgue. In: SILVA, T. T (Org.) Antropologia do Ciborgue: as vertigens do pós-humano. Belo Horizonte: Autêntica, 2000. 
NIETZSCHE, F. W. Assim falou Zaratustra. São Paulo: Martin Claret, 2002.

Enviado em Maio/2012

Aprovado em Abril/2013 